\title{
Ueber eine neue Verfälschung des Cremor tartari.
}

Blengini untersuchte einen mit Milchzucker verfälschten gereinigten Weinstein. Der Verkäufer eines solchen Gemisches der beiden Substanzen zu gleichen Theilen gewinnt davon über das Doppelte.

Man erkennt diese Verfälschung an dem Löslichkeitsverhältniss in Wasser, an dem süsslichen Geschmack und der ziegelrothen Farbe, welche arsenige Säure damit hervorbringt. Ferner bildete sich durch Einwirkung von Salpetersäure in gelinder Wärme Schleimsäure. (Giorn. di Farmacia di Torino. - Journ. de Pharm. d'Anvers. Mars 1854.)

A. $O$.

\section{Ueber ein einfaches Verfahren zur Krkennung der Aechtheit des Jalappen- und Scammoniumharzes.}

A. Buchner empfiehlt folgendes Verfuhren, um die Aechtheit des käuflichen Jalappenharzes durch nachstehenden Versuch sogleich zu erkennen.

Man löst etwas vom Harz in verdïnnter Kali- oder Natronlauge auf, erwärmt die Auflösung lkurze Zeit, filtrirt, wenn es nöthig ist, dieselbe und sättigt hierauf mit verdünnter Schwefelsäure. Ist das Harz rein, so entsteht höchstens nur eine geringe Opalisirung, während, wenn es nur sehr wenig eines gewöhnlichen Harzes, z. B. Colophonium oder Guajakharz beigemischt enthïlt, sogleich ein starker harziger Niederschlag gebildet wird.

Eine Substituirung des Harzes der ächten Jalappenknollen durch dasjenige aus der Wurzel von Ipomoea orizabensis, den sog. Jalappenstengeln, kann auf diese Weise aber nicht erkannt werden.

Obiges Verfahren lässt sich auch zur schnellen Erkennung einer Verfälschung des Scammoniums mit einem der gewöhnlichen Harze benutzen. Man erwärmt das zerreibbare Scammonium mit Kalilauge, filtrirt und übersättigt mit verdünnter Schwefelsäure. Bei ächtem aleppischem Scammonium entsteht nur eine Opalisirung oder höchstens eine schwache Trübung; bei einem mit Colophonium oder einem andern gewöhnlichen Harze verfälschten aber ein beträchtlicher harziger Niederschlag. Noch besser fällt der Versuch aus, wenn man das Scammonium mit Alkohol auszieht, die alkoholische Lösung durch Schütteln mit Knochenkohle entfärbt, filtrirt, verdampfen lässt und dann mit dem so gereinigten Harze die Probe vor- 